\title{
SITUAÇÕES DE MORTE E MORRER E AS PSICOPATOLOGIAS ENVOLVIDAS EM CRIANÇAS E ADOLESCENTES REFUGIADOS - UMA REVISÃO SISTEMÁTICA COM METANÁLISE
}

\author{
Joselito Batista Dias ${ }^{1}$, Modesto Leite Rolim Neto ${ }^{2}$
}

Introdução: São muito raros os estudos sobre os transtornos mentais envolvidos em situações de morte e morrer, principalmente quando se considera as psicopatologias em crianças e adolescentes refugiados. A consequência é a pequena disponibilidade de dados e ausência de um perfil epidemiológico real, dificultando a adequação das políticas de saúde e a avaliação da efetividade dessas ações junto os sujeitos expostos a situação de refúgio. Método: Revisão sistemática com metanálise seguindo o protocolo PRISMA (Preferred Reporting Items for Systematic Review and Meta-Analyse), de 2015 a 2018, através das bases de dados: LILACS - Latin American and Caribbean Health Sciences Literature, SciELO - Scientific Eletronic Library OnLine e BVS - Virtual Health Library. A análise envolveu as seguintes palavras-chave: "modelos de atenção primária e secundária em saúde mental", "criança", "adolescentes", "políticas e serviços em saúde mental" e "refugiados" através do operador booleano \# and. A literatura cinzenta (literatura não controlada por editores científicos ou comerciais), também foi utilizada através da busca manual (handsearching). Resultados: Uma análise conjunta das estratégias pontuadas nos artigos analisados mostra um Odds Ratio combinado de 1,291 IC [1,054 - 1,582] o que demonstra a falta de efetividade do uso das estratégias na elaboração de aparatos institucionais no campo de saúde mental em situações de morte e morrer em crianças e adolescentes refugiados. O valor de "p" da distribuição qui-quadrado resultou em 0,9753 o que rejeita a hipótese de associação entre a presença de estratégias em saúde mental e cuidados paliativos em situações de refúgio. Conclusão: Uma análise combinada de todas as estratégias pontuadas nos estudos analisados demonstra a falta de efetividade da utilização das estratégias na elaboração de aparatos institucionais no campo de saúde mental e processos de morte e morrer. Alguns desafios, porém, permanecem no âmbito do refúgio, tais como fomento da rede de assistência, domínio e ampliação dos recursos diagnósticos e terapêuticos, estímulo à reinserção social, abordagem conjunta da condição clínica, mental e socioeconômica, capacitação dos profissionais de saúde e intervenções em observância à autonomia e às individualidades do sujeito em situações limítrofes naquilo que circunda os indicadores de estresse envolvidos na morte e o morrer.

Palavras-Chave: Modelos de atenção primária e secundária em saúde mental, Criança, Adolescentes, Políticas e serviços em saúde mental, Refugiados.

\footnotetext{
${ }^{1}$ Universidade Católica de Santos, UNISANTOS;

${ }^{2}$ Faculdade de Medicina de Juazeiro do Norte - FMJ/Estácio;

Autor correspondente: val_luanna@hotmail.com. 